\title{
Oxidative Stress and Microglial Cells in Parkinson's Disease
}

\author{
Lynda J. Peterson and Patrick M. Flood \\ North Carolina Oral Health Institute, The University of North Carolina at Chapel Hill, CB\#7454, Chapel Hill, \\ NC 27599-7454, USA \\ Correspondence should be addressed to Patrick M. Flood, pat_flood@dentistry.unc.edu
}

Received 4 November 2011; Revised 3 January 2012; Accepted 9 January 2012

Academic Editor: Luc Vallières

Copyright ( 2012 L. J. Peterson and P. M. Flood. This is an open access article distributed under the Creative Commons Attribution License, which permits unrestricted use, distribution, and reproduction in any medium, provided the original work is properly cited.

\begin{abstract}
Significant evidence has now been accumulated that microglial cells play a central role in the degeneration of DA neurons in animal models of PD. The oxidative stress response by microglial cells, most notably the activity of the enzyme NADPH oxidase, appears to play a central role in the pathology of PD. This oxidative stress response occurs in microglia through the activation of the ERK signaling pathway by proinflammatory stimuli, leading to the phosphorylation and translocation of the p47 $7^{\text {hox }}$ and p67phox cytosolic subunits, the activation of membrane-bound PHOX, and the production of ROS. Therapeutic antiinflammatories which prevent DA neurodegeneration in PD, including anti-inflammatory cytokines, morphinan compounds, NADPH oxidase inhibitors, NF- $\kappa$ B inhibitors, and $\beta 2$-AR agonists, all function to inhibit the activation of the PHOX in microglial cells. These observations suggest a central role for the oxidative stress response in microglial cells as a mediator or regulator of DA neurodegeneration in PD.
\end{abstract}

\section{Neurodegeneration and Inflammation in Parkinson's Disease}

Parkinson's disease (PD) is a progressive degenerative disorder of the central nervous system (CNS) that leads to impairment of motor skills and speech, as well as other functions [1]. In the United States, it is estimated that between $0.1-0.2 \%$ of all individuals are at some stage in the progression of Parkinson's Disease. This rate is somewhat higher in the elderly and those experiencing head trauma. There are several different forms of Parkinson's disease, with the most common being either the familial or the idiopathic forms. The familial forms result from alterations in genes such as $\alpha$-synuclein, LRRK2, parkin, PINK-1, or DJ-1 [27], while the idiopathic forms arise from environmental factors such as exposure to toxins, head trauma, infection, or unknown etiology [8-13]. While onset before age 30 is rare, up to $10 \%$ of cases of idiopathic PD begin by age 50 [14]. The primary symptoms of PD are caused by the insufficient formation and action of dopamine, and they are manifest by decreased stimulation of the motor cortex by the basal ganglia. The loss of dopamine, which is predominantly produced by the DA neurons within the substantia nigra $(\mathrm{SN})$ region and striatum of the brain, results in tremors, muscle rigidity, cognitive dysfunction, changes in speech patterns, muscle rigidity, and a dynamic progressive dysfunction that can lead to a total loss of all physical movement and ultimately death [7, 15-18].

Although the disease mechanisms that ultimately cause PD are still not fully understood, it is believed that the progressive nature of Parkinson's disease is characterized by chronic inflammation-induced neurodegeneration of dopamine-producing neurons within the $\mathrm{SN}$ and striatum $[13,19-23]$. It is now well documented that microglial activation results in the loss of dopaminergic neurons (DAneurons) in patients with PD [24-28]. Additionally, levels of proinflammatory cytokines, including TNF $\alpha$, IL- $1 \beta$, IL6 , as well as reactive oxygen species (ROS) are elevated in the brains and peripheral blood mononuclear cells (PBMCs) of patients with PD [29-31]. Nitrite in the cerebrospinal fluid as well as increased expression of inducible nitric oxide synthase (iNOS) within the SN has also been found in PD patients [32,33], contributing to strong evidence of oxidative stress in the SN of PD patients [25,34]. These observations, taken together suggest that progressive PD is driven by the inflammatory response of microglial cells, and that the action 
of these cells, including oxidative stress responses and ROS production, may play a key role in the neurodegeneration seen in PD.

\section{Microglial Cells and Oxidative Stress in Parkinson's Disease}

The etiology of idiopathic PD now suggests that chronic production of inflammatory mediators by microglial cells, $[31,32,35]$, particularly the generation of ROS and NO by activated microglia $[23,33,34,36,37]$, mediates the majority of DA-neuronal tissue destruction [38]. Microglia are the resident macrophages of the brain and as such play critical roles in the development and maintenance of the neural environment [39]. Although microglia continually survey the surrounding tissue, they remain in essentially a quiescent state under tight regulation until they become activated in response to perturbations in the brain's microenvironment or changes in the neuronal structure. Resting microglia continually "sense" conditions in the surrounding tissue by extending and contracting their cellular processes, and their encounter with extracellular triggers such as those from pathogens, structurally or genetically altered proteins, and dead or dying neuronal cells will activate a strong proinflammatory response $[39,40]$. Once activated, microglia undergo morphological changes as well as phenotypic alterations in gene expression and production/activation of signaling molecules. More importantly, microglia will mount a series of responses, starting with the oxidative stress response, to produce mediators which help to eliminate the source of these proinflammatory signals. These activated microglia have dichotomous roles in neuroinflammation in that they can both mediate the inflammatory response by producing mediators which function to clear the source of the inflammatory stimuli, and they can regulate the inflammatory response by perpetuating the proinflammatory response through the continued release of inflammatory products which function to activate and regulate microglia and astrocyte responses. Conversely, when the inflammatory stimuli have been removed, microglia can function to promote neurogenesis through the release of neurotrophins and anti-inflammatory cytokines, potentially leading to neuroregeneration and wound healing within the SN and striatum $[39,41-44]$.

There are a number of pro-inflammatory stimuli by which microglial cells can be activated to mediate DAneurotoxicity in rodent models of PD. Agents that directly activate microglia have been shown to lead to the loss of DAproducing neurons both in vitro and in vivo. These include LPS $[37,45,46]$ and nitrated- $\alpha$-synuclein [47]. In addition, several direct neurotoxins, such as 1-methyl-4-phenyl1,2,3,6-tetrahydropyridine (MPTP) and 6-hydroxydopamine (6-OHDA), can activate microglia through a process called reactive microgliosis, which leads to exacerbation of DAneuron neurotoxicity $[25,28,48-51]$. There is also a strong correlation in human patients between proinflammatory signals in the brain, including inflammation caused by traumatic brain injury [52] and infection [53, 54], and the ultimate onset of PD. Once activated, microglial cells produce a wide variety of inflammatory mediators which serve to mediate an innate immune response, including ROS and the related NO. NF- $\kappa \mathrm{B}$ and MAP-kinase signaling pathways control gene expression of many of these proinflammatory cytokines, chemokines, and enzymes that produce these secondary inflammatory mediators [54-57]. Our recent work, and that of others using rodent models of DA neurodegeneration, has shown that the oxidative stress response plays a central role in the etiology of PD [5861] and that anti-inflammatory therapeutics that inhibit the oxidative stress response in microglial cells can be neuroprotective [59-61]. Furthermore, animal studies have demonstrated that the generation of ROS is an upstream event which regulates the production of other proinflammatory factors such as TNF $\alpha$ and IL- $1 \beta$ through its regulation of the transcription factor NF- $\kappa B[62,63]$. Furthermore, the postmortem detection of elevated levels of ROS and NO, and evidence of oxidative-stress-mediated damage in the brain of PD patients, strongly implies microglial-induced ROS and NO involvement in the chronic degenerative process in vivo. Therefore, it appears that the oxidative stress response in microglial cells may be an important component of both the DA neurodegenerative response, and in the maintenance of the chronic pro-inflammatory response seen in PD patients.

Further evidence for the central role of ROS in DA neurodegeneration and PD is found in animal model systems which exhibit hyperactive microglial cells. In the normal, healthy brain, microglia are in intimate contact with neurons which maintain the microglia in the quiescent state by means of membrane-bound and secreted signaling molecules [64-66]. The most important of these suppression signals appears to be CD200 expressed on neurons and endothelial cells within the CNS and its interaction with the receptor CD200R, which is expressed on the microglia $[64,67,68]$. Interaction of CD200 and the receptor, between contacting neurons and microglia, helps to maintain the microglia in the inactive state $[64,67-71]$, since mice lacking expression of CD200 exhibit microglia with morphology typical of activated cells as well as heightened expression of activation markers CD11b and CD45 [69]. Microglial cells from CD200 deficient mice also release elevated levels of inflammatory mediators TNF $\alpha$, ROS, and NO subsequent to an immune challenge [69]. A rat model of PD using mixed cultures of mesencephalic neurons and microglial cells showed that treatment with a function neutralizing antibody to CD200R enhances the susceptibility of DA neurons to neurotoxic insult [71]. Similar results were found when the mixed cultures were subjected to insult by the addition of iron in another cellular model of PD [71]. Significantly, the neutralizing antibody-treated cultures showed increased levels of NADPH oxidase-mediated superoxide production which was found to be the critical factor in DA-neuron neurotoxicity. Treatment with the superoxide inhibitors, superoxide dismutase (SOD) or catalase, attenuated the loss of DA neurons in mixed cultures treated with the antiCD200R antibodies plus neurotoxins. Similarly, the NADPH oxidase inhibitor, apocynin, also blocked the antibodytoxin effects on DA neuron survival [71]. Impairment 
of CD200-CD200R interaction is functionally associated with microglial activation and the increased death of DA neurons which is induced by enhanced NADPH oxidasemediated superoxide production as the killing factor $[69,71]$. Changes in the microenvironment at the cell surface of the microglia are thus amplified into intracellular signals that result in release of ROS which then can act as both direct effectors in neurotoxicity, and as secondary signaling factors that participate in stimulation of the production of other neuroinflammatory mediators.

NADPH oxidase (PHOX) is the major enzyme for the production of extracellular superoxide in immune cells and is highly expressed in microglia. It has been found that the activation of microglia by pro-inflammatory stimuli such as lipopolysaccharide (LPS) can lead to activation of PHOX through an ERK-dependent mechanism via the phosphorylation and translocation of cytosolic components of PHOX, including the $\mathrm{p} 47^{\text {phox }}$ and $\mathrm{p} 67^{\text {phox }}$ cytosolic subunits of PHOX [61]. We have found that phosphorylation of Ser ${ }^{345}$ on $\mathrm{p}^{4} 7^{\text {phox }}$ is a prerequisite to the degeneration of DA neurons both in vivo and in vitro, and that significantly decreased DA neurotoxicity is seen in both $\mathrm{PHOX}^{-/-}$mice (in vivo) and $\mathrm{PHOX}^{-/-}$midbrain neuron/glia cultures (in vitro) than in $\mathrm{PHOX}^{+/+}$controls [72]. Furthermore, DPI (diphenylene iodonium), a widely used NADPH oxidase inhibitor, has been found to have significant therapeutic effects in a number of inflammatory diseases, including liver disease, exothermia, and EAE [73-76], and now appears to have efficacy as a therapeutic to prevent DA neurodegeneration in PD (see below). These observations suggest that the oxidative stress response, more specifically the one mediated by NADPH oxidase, may have a central role in DA neurodegeneration.

\section{ROS and Neuroinflammation}

Reactive oxygen species (ROS) include molecules such as superoxide $\left(\mathrm{O}_{2}{ }^{-}\right)$and hydrogen peroxide $\left(\mathrm{H}_{2} \mathrm{O}_{2}\right)$. In addition, $\mathrm{H}_{2} \mathrm{O}_{2}$ is associated with the generation of nitric oxide (NO), another reactive species. While ROS have some essential roles in normal cell functions [77], they are more associated with their pathological effects that ultimately lead to protein and cellular damage as well as cell death [78-81]. Extracellular insults, which include inflammation, stimulate production of ROS to hyperphysiological concentrations that results in oxidative stress. Under oxidative stress, redox reactions modulate proteins and generate changes in intracellular and intercellular signaling pathways that drive changes in cellular responses [71]. Different levels of oxidative stress induce disparate consequences for cellular function including proliferation, differentiation, and cell death. At high levels of ROS production, proteins become inactivated or damaged resulting in cellular degeneration and death. In this context, redox-sensitive proteins transduce redox changes into signals that induce cellular responses. Thus, proteins can be viewed as "redox sensors" that can affect modifications in their own localization, abundance, and activities [71]. Redox-modified proteins can also affect changes (conformational, posttranslational, etc.) in other proteins as is the nature of signaling pathways $[71,82]$. At nonlethal levels, the redox state of the proteins and cells can be reversible and the molecular basis of the redox changes occurs mainly on the cysteine residues. Signaling events, initiated by thiol-based redox changes on the cysteines, emanate from the protein and are transmitted to other molecules in the signaling pathway via conformational changes, posttranslational modifications, and translocations. In this way, the thiol-cysteines have been called "molecular switches" and these actions have been elucidated for various components of signaling pathways including proteases, kinases, and transcription factors [71].

Among the transcription factors that are responsive to redox-based signaling in microglial cells is NF- $\kappa \mathrm{B}$ [83]. NF$\kappa \mathrm{B}$ consists of two subunits which can vary according to the signaling pathway that is activated by cellular events $[54,55]$ (see Figure 1). Rel A (p65) and p50 are the subunits that form the heterodimer in the canonical NF- $\kappa$ B pathway, and the p65/p50 dimer normally remains inactive in the cell's cytoplasm in complex with the I $\kappa \mathrm{B}$ inhibitor protein $[54,55]$. When the pathway is induced by some stimuli such as oxidative stress, I $\kappa \mathrm{B}$ is degraded and NF- $\kappa \mathrm{B}$ is released to translocate to the nucleus where it binds DNA to activate transcription of genes $[54,55,84]$. It has been shown that the presence of ROS can induce activation of NF- $\kappa \mathrm{B}$ in the cytoplasm but can conversely inhibit NF- $\kappa \mathrm{B}$ activity in the nucleus [83]. Oxidation of p50 within the DNAbinding domain inhibits DNA binding thus mediating direct ROS regulation of NF- $\kappa$ B transcriptional activity. ROS can also indirectly control NF- $\kappa \mathrm{B}-\mathrm{DNA}$ binding by regulating serine phosphorylation of p65 which is necessary for RelADNA interaction [85]. However, ROS could both inhibit and promote NF- $\kappa \mathrm{B}$ activity in what has been suggested as a biphasic redox-sensitive response [86-89]. When only slight increases in ROS levels are induced in the cytoplasm, then small increases in $\mathrm{I} \kappa \mathrm{B}$ degradation occur. Excessive ROS, especially when present in the nucleus, results in oxidation-mediated inhibition of NF- $\kappa$ B-DNA binding [89]. This suggests that moderate increases in ROS induce $\mathrm{I} \kappa \mathrm{B}$ degradation, leading to transcriptional activation which is usually prosurvival. Conversely, when ROS becomes excessive in the microenvironment, the nucleus becomes oxidative which inhibits NF- $\kappa \mathrm{B}$ transcriptional activity and abolishes prosurvival gene expression [89]. What this means for ROS and NF- $\kappa \mathrm{B}$-mediated neurodegeneration is not clear since inhibition of NF- $\kappa$ B activity or blocking ROS production has been shown to promote neuronal survival in both cellular and animal models of PD [27, 90]. Since activated microglia are a part of the clearance phase of an inflammatory response and are additionally an important source of neurotrophins in neurogeneration, microglial survival at moderate levels of ROS is crucial to their physiological function. Significantly, these cysteine-thiol-based oxidative responses to ROS are reversible suggesting signaling mechanisms similar to phosphorylation and dephosphorylation of molecular switches [89]. As with the case of phosphorylation-based signaling, ROS signaling could have stimuli-specific and cell-typespecific mechanisms. 


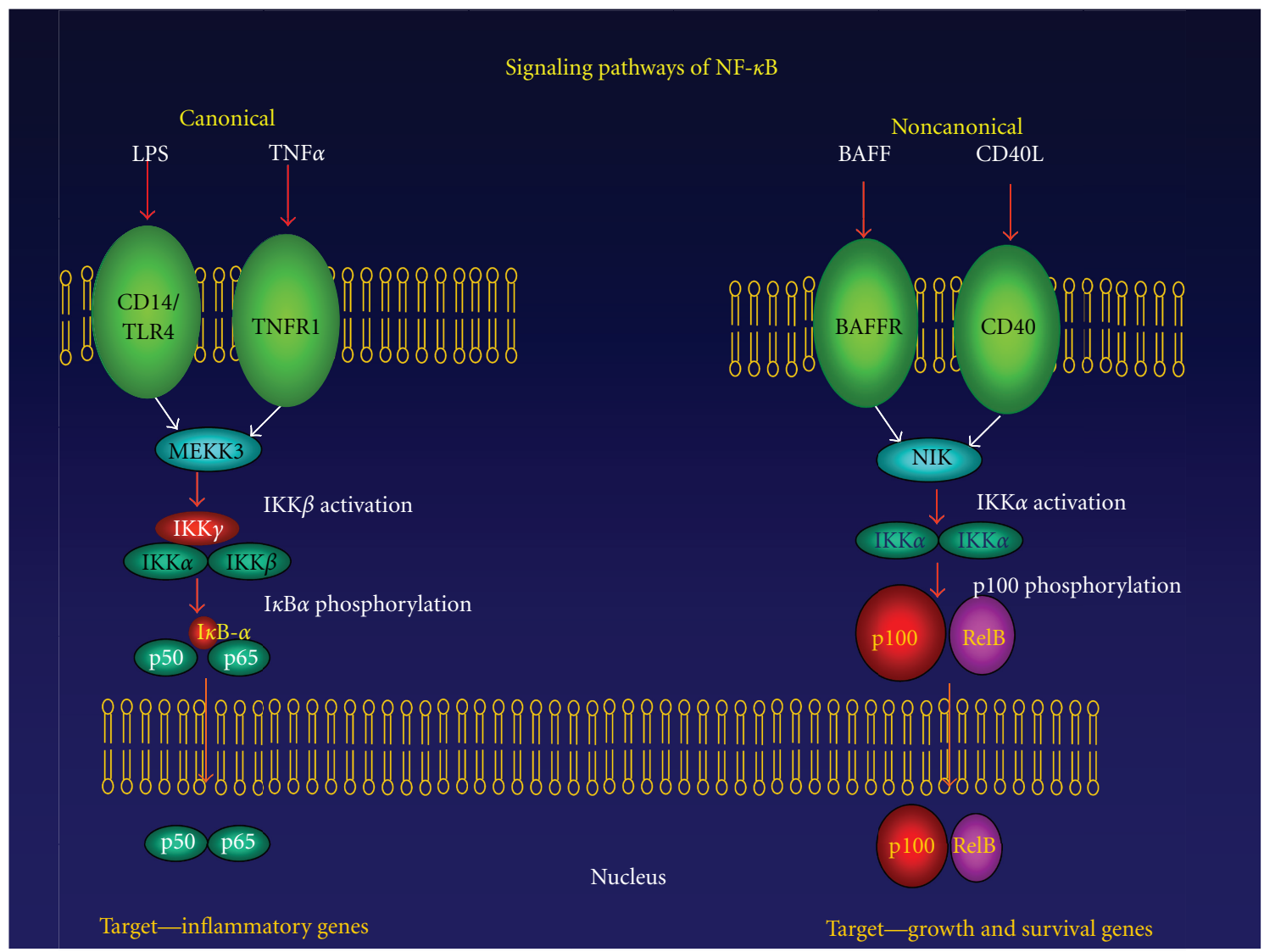

Figure 1: Canonical and noncanonical pathways of NF- $\kappa$ B activation. Proinflammatory activation signals such as LPS or TNF $\alpha$ activate the canonical pathway through the activation of the IKK complex, which includes the subunits IKK $\gamma$ (NF- $\kappa \mathrm{B}$ essential modulator, or NEMO), $\operatorname{IKK} \alpha$, and IKK $\beta$. This complex then phosphorylates $\operatorname{IkB} \alpha$ (the NF- $\kappa \mathrm{B}$ inhibitor), which causes it to be ubiquitinated and proteolytically cleaved by the proteosome, releasing the p50/p65 heterodimer to be translocated to the nucleus, where it transcriptionally activates proinflammatory genes, including $\mathrm{p} 47$ and p67 of the NADPH oxidase complex. Growth and differentiation signals such as BAFF and CD40L activate the noncanonical pathway, which is initiated by NF- $\kappa$ B inducing kinase (NIK), which phosphorylates the IKK $\alpha$ homidimer complex which does not require either IKK $\gamma$ or IKK $\beta$, which subsequently phosphorylates the p100 subunit of the p100/RelB complex. The p100 protein is cleaved, which allows the p52/RelB complex to translocate to the nucleus and activate a number of growth and survival genes in target cells.

In phagocytes such as microglia, ROS production can be generated from several sources including intracellular peroxidases, oxidative processes in mitochondria, and NADPH oxidase activity at the cell-surface membrane [24]. Under physiological conditions, superoxide, hydroxyl radi$\mathrm{cal}$, and hydrogen peroxide are normal byproducts of oxygen metabolism by mitochondria $[77,89]$. Superoxide is generated from mitochondrial complexes I and III of the electron transport chain and can be reduced to $\mathrm{H}_{2} \mathrm{O}_{2}$ which is also produced by peroxisomes $[89,91]$. Normally, the catalase in peroxisomes decomposes $\mathrm{H}_{2} \mathrm{O}_{2}$ thus preventing its toxic accumulation in the cell. Under pathological conditions, catalase activity is downregulated, $\mathrm{H}_{2} \mathrm{O}_{2}$ is released into the cytosol increasing oxidative stress and, in the presence of reduced metals, is converted to the hydroxyl radical. Superoxide can also react with nitric oxide to produce peroxynitrite $(\mathrm{PN})$ which is an extremely active oxidizing agent $[91,92]$. Excess production of reactive oxygen and nitrogen species in PD is thought to damage lipids, proteins, and DNA as shown postmortem by high levels of lipid peroxidation products, oxidized and damaged proteins, as well as oxidized DNA in the CNS of PD patients $[18,93]$. $\mathrm{PN}$-modified proteins have been found to accumulate in the Lewy bodies of the cells in PD brains and PN has been shown to inhibit complex-I-mediated cellular respiration $[82,91,92,94-96]$.

\section{Successful Therapies to DA Neurodegeneration Also Target the Oxidative Stress Response}

Emerging evidence demonstrates that numerous inflammatory mediators such as ROS free radicals, NO, and other products of activated immune cells can play a role in the degeneration of $\mathrm{SN}$ dopamine-producing neurons in several rodent models of PD [36, 79]. Therefore, it is likely that treatment with anti-inflammatory reagents directed at these proinflammatory targets could also potentially halt or slow DA neurodegeneration in these rodent models. For 
example, steroidal anti-inflammatory drugs (SAIDs) such as dexamethasone have been reported to show neuroprotection against MPTP- or LPS-induced toxicity in rodents [97, 98]. Nonsteroidal anti-inflammatory drugs (NSAIDS) such as aspirin and ibuprofen reduce inflammation by inhibition of COX activity and have been found to be modestly effective at slowing the progression of neurodegeneration in the MPTP rodent model [99]. Recently, strategies that block the canonical form of the proinflammatory transcription factor $\mathrm{NF}-\kappa \mathrm{B}[27,100]$, and activating the peroxisome proliferatoractivated receptor- $\gamma(\operatorname{PPAR} \gamma)[101,102]$, have shown beneficial effects in the modulation of inflammatory responses in mice and rats. We have used five relatively novel approaches in anti-inflammatory therapy to prevent DA neurodegeneration in rodent models of $\mathrm{PD}$, and these approaches include (1) the use of endogenous anti-inflammatory cytokines IL10 or TGF $\beta 1$, (2) the use of morphinan-related compounds; (3) the use of PHOX inhibitor DPI; (4) the targeting of IKK, a major component of the signaling pathway activating the canonical form of NF- $\kappa \mathrm{B}$, which is the major transcriptional regulator of inflammation; (5) the use of $\beta-2$ adrenergic receptor $(\beta-2 \mathrm{AR})$ agonists. While none of these studies have yet been used on human patients, we will review the evidence suggesting that these successful therapies in rodents target the oxidative stress response in microglia. Furthermore, the effect of L-DOPA therapy on microglial-mediated oxidative stress responses in rodent models of DA neurodegeneration and in patients with PD will be reviewed.

\section{Therapies Using Anti-Inflammatory Cytokines IL-10 and TGF $\beta 1$}

When ROS is the product of activated microglial cells found in the proinflammatory state, endogenous antiinflammatory cytokines are also produced by microglial cells following elimination of the proinflammatory signal to provide a negative-feedback mechanism which converts the microglia to a wound-healing phenotype. [103, 104]. IL10 and TGF $\beta 1$ are two major anti-inflammatory cytokines that regulate the inflammatory response by inhibiting the production of proinflammatory mediators by microglia. Studies using exogenously supplied IL10 and TGF $\beta 1$ have shown potent effects at inhibiting the canonical signaling pathway of $\mathrm{NF}-\kappa \mathrm{B}$ and in reducing neurotoxicity induced by either LPS or MPTP in PD models $[60,104-106]$. We have found using an in vitro model of PD that the addition of IL-10 to a mixed glial cell-neuron cell culture abrogated the degeneration of the neuron cells induced by either LPS or MPTP [60], and this inhibitory effect was mediated through its inhibition of the production of extracellular superoxide in the microglia cells within the mixed cell culture [105]. These in vitro effects of IL-10 are confirmed by in vivo results from a 6-OHDA rat model of PD. In this model, sustained administration of IL10 via a viral vector significantly protected DA-neuron from death and ameliorated behavioral deficits induced by intrastriatal delivery of 6-OHDA [106]. Likewise, in vitro or in vivo studies have shown that TGF $\beta 1$ can also protect neurons from cell death induced by oxidative stress [107]
We have strong evidence that the neuroprotective effects of both IL-10 and TGF $\beta 1$ are mainly due to their inhibition of NF- $\kappa \mathrm{B}$ and ROS production in microglia during initial activation or in reactive microgliosis $[60,108]$. TGF $\beta 1$ also prevents the ERK-dependent phosphorylation on $\mathrm{p} 47^{\text {phox }}$ in the microglial cells and blocked translocation and assembly of the PHOX molecular complex to the plasma membrane. Inhibition of PHOX activation consequently reduced oxidase activities induced by LPS [108]. While the complete in vivo roles of IL10 and TGF $\beta 1$ in the prevention of DA neurodegeneration in PD remain to be determined, both appear to function, at least in part, by the inhibition of oxidative stress responses in microglia.

\section{Morphinan-Based Anti-Inflammatory Therapeutics}

Several studies using PD animal models or in vitro cell cultures have shown that the morphinan compound dextromethorphan $(\mathrm{DM})$ and its metabolites are neuroprotective due to their anti-inflammatory properties and inhibitory function towards microglia activation $[59,109,110]$. DM inhibits microglia activation and is neuroprotective when administered daily to mice that had been injected with MPTP [109]. Another metabolite of DM, 3-hydroxymorphinan (3$\mathrm{HM}$ ) was shown to have the greatest potency (of several tested methorphanins) for attenuating the loss of DA neurons in the $\mathrm{SN}$, as well as restoring motor functions in the same MPTP-mouse model of PD [110], and clinical trials using 3-HM are currently underway in patients with progressive $\mathrm{PD}$. The use of 3-HM in vitro protected neuronal cells in mixed glial-neuronal cells cultures by reducing MPTP-induced microgliosis and decreasing the production of ROS. [111]. Likewise, the use of other morphinan compounds, including sinomenine, a morphinanrelated alkaloid compound purified from a medicinal plant (Sinomenine acutum) that has been traditionally used to treat inflammatory disorders $[112,113]$, and $d$-morphine, the dextrorotatory form of the narcotic $l$-morphine, both show strong neuroprotective effects when used both in vitro and in vivo. In all cases with these morphinan compounds, the major effect of these compounds was to inhibit microglial inflammatory responses through the inhibition of both NF- $\kappa \mathrm{B}$ activation and subsequently ERK phosphorylation, preventing the $\mathrm{p} 47^{\mathrm{phox}}$ from translocating to the plasma membrane where the complex becomes activated, and resulting in the reduction of the release of extracellular ROS [108].

\section{Therapies using NADPH Inhibitors}

Diphenyliodonium (DPI), a NADPH oxidase inhibitor, shows potent anti-inflammatory and neuroprotective effects in primary midbrain cultures, and in the LPS rodent model of PD in vivo [73]. Mechanistic studies revealed that DPIelicited effects were mediated by the inhibition of LPSinduced microglial ROS production and the subsequent 
release of pro-inflammatory cytokine TNF $\alpha$, and the production of nitric oxide. Further studies showed that DPI significantly reduced LPS-induced ERK phosphorylation, and the subsequent phosphorylation and translocation of the p47phox cytosolic subunit $[73,108]$. Taken together, our results demonstrate that DPI exerts potent anti-inflammatory and neuroprotective effects by inhibiting microglial activation through the inhibition of ERK-regulated PHOX activity.

\section{Therapies Targeting IKK/NF- $\kappa$ B}

Given the importance of the canonical form of transcription factor NF- $\kappa \mathrm{B}$ in both the production of the components of the oxidative stress response (p47 and p67 are regulated by NF- $\kappa \mathrm{B}$ ), and in the regulatory effects of ROS in activating microglia (NF- $\kappa \mathrm{B}$ controls ERK activity induced by LPS signaling, Figure 2), inhibitors of the canonical pathway of NF- $\kappa \mathrm{B}$ should provide strong evidence of the role of oxidative stress responses in PD. Therefore, a key strategy for inhibiting neuroinflammation is to target the canonical pathway of NF- $\kappa$ B activation without inhibiting the noncanonical pathway, which is mainly involved in cell growth, differentiation, and cell survival. In fact, specific NF$\kappa \mathrm{B}$ inhibitors have recently been demonstrated to halt the progression of neurodegeneration induced by the neurotoxin MPTP in murine models of PD [27], or by activation of CNS inflammation by the intracranial injection of LPS [90]. The approach was to inhibit the canonical signaling pathway of NF- $\kappa \mathrm{B}$ without inhibiting the noncanonical pathway of activation by targeting the unique kinase complex of the canonical pathway called IKK (for the difference between the canonical and noncanonical signaling pathway, see Figure 1). Utilizing a peptide against IKK $\gamma$, which is directed against the NEMO-binding domain (NBD peptide) prior to injection of MPTP into mice significantly, inhibits the activation of NF$\kappa \mathrm{B}$ within the midbrain region [27]. This inhibition of NF$\kappa \mathrm{B}$ activation is accompanied by a concomitant reduction in NADPH activity and ROS production, as well as the expression of microglial cell activation marker CD11b. This protection was also seen if administration of NBD peptide was done 2 days after injection of MPTP, suggesting that NBD peptide can be used therapeutically to slow down or halt the progression of DA neurodegeneration in MPTPtreated animals [27].

Likewise, use of a small molecule inhibitor of $\operatorname{IKK} \beta$, called Compound $\mathrm{A}$, had identical results in inhibiting ROS production from microglial cells in vitro, and in protecting DA neurons from LPS-induced neurodegeneration in vitro and in vivo [90]. While the specific inflammatory mediator(s) targeted by of NF- $\kappa$ B inhibition within microglial cells remains to be determined, these data suggest that inhibition of ROS production using NF- $\kappa$ B inhibitors may be a key component of the neuroprotection seen in PD patients [27].

\section{Therapies Utilizing $\beta 2$-AR Agonists}

A recent family of compounds that have shown the potential to reduce inflammation and DA neurodegeneration in animal models are the long-acting $\beta 2$-adrenergic receptor $(\beta 2-\mathrm{AR})$ agonists [114-120]. These $\beta 2$-AR agonists exist in both short-acting and long-acting forms, and pharmacological studies have indicated that long-acting agonists are quite effective at inhibiting the inflammatory responses of macrophage and microglial cells. We have found that many of these long-acting agonists, including salmeterol (found in Advair) and formoterol (found in Symbicort) can inhibit the microglial oxidative stress response and inflammatory mediator production, as well as inhibiting DA neurodegeneration in vitro [121]. Furthermore, therapeutic administration of the long-acting $\beta 2$-AR agonist salmeterol significantly protects DA neurons against LPS- and MPTPinduced cytotoxicity in vivo [121]. It is important to note that the dosages used to treat progressive neurodegeneration induced by either LPS or MPTP in mice are far below those currently used to treat patients with COPD, the current indication for this class of compounds (121), and we have previously found that exposure of macrophages and microglial cells to high or chronic doses of salmeterol can actually exacerbate rather than inhibit the inflammatory and oxidative stress response in these cells [122]. Our mechanistic studies indicate that the low-dose anti-inflammatory effects of salmeterol are mediated through the inhibition of both MAPK and NF- $\kappa$ B signaling pathways in activated microglia, function independently of the canonical GPCR/cAMP/PKA signaling pathway, and mediate their effects only in $\mathrm{PHOX}^{+}$ cells. Therefore, it appears that these agonists function at least in part through the inhibition of ROS production by NADPH oxidase and add additional evidence of the central role of the oxidative stress response in microglia as a key component of DA neurodegeneration in PD. Furthermore, although no clinical or epidemiological data yet exists to suggest that the use of $\beta 2$-AR agonists has any beneficial effect on slowing or stopping the progression of PD in human patients, our data suggests that this class of therapeutics, particularly salmeterol, may be a new and highly effective treatment to halt the progression of not only PD but also other neuroinflammatory diseases. However, given the potential for both pro- and anti-inflammatory reactions on microglial cells, therapeutic regimens using $\beta 2$-AR agonists in the treatment of PD will need to be carefully developed and studied to determine the ultimate efficacy of these compounds.

\section{Therapy Utilizing L-DOPA}

Currently, it is believed that the progression of PD is also due to oxidative stress damage not only from microglia, but also from within the neurons themselves due in large part to increased dopamine turnover, [123, 124]. The current standard of care for the treatment of PD is the administration of L-3,4-dihydroxyphenylalanine (L-DOPA), which in the short term relieves many of the symptoms of PD but has also been found to induce an oxidative stress response in DA-neurons [125-127]. It is believed that L-DOPA at high doses actually leads to cell death in neurons due to its activation of apoptosis through the ASK1 and MAP-K 


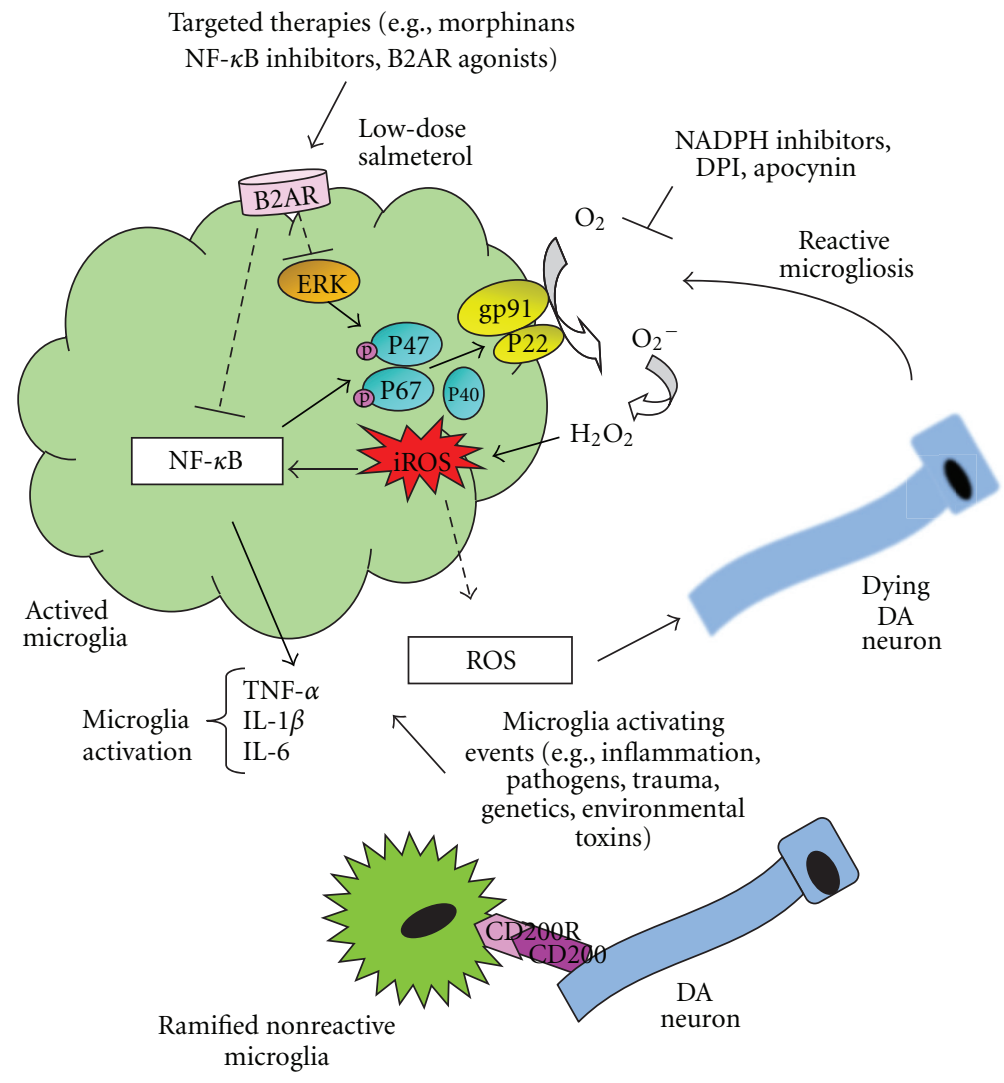

FIGURE 2: Chronic production of inflammatory mediators by microglial cells, particularly the generation of ROS and NO by activated microglia, mediates the majority of DA-neuronal degeneration and cell death. As resident brain macrophages, microglia continually survey the surrounding tissue where they remain in an inactive, quiescent state under tight regulation such as by the interaction of cell-surface molecules CD200 (expressed on neurons) and CD200R receptor on the microglia. Microglia become activated when they encounter extracellular triggers such as those from the pathogens, structurally or genetically altered proteins, toxins, and dead or dying neuronal cells. Activated microglia generate a strong proinflammatory response including the production of inflammatory cytokines (e.g., TNF $\alpha$, IL-6, IL-1 $\beta$ ) and an oxidative stress response. Most notably, the activity of the oxidative-stress enzyme, NADPH oxidase, appears to play a central role in the pathology of DA-neuron death and the progression of PD. This oxidative stress response occurs in microglia through the activation of the ERK signaling pathway by proinflammatory stimuli, leading to the phosphorylation and translocation of the p47phox and p67phox cytosolic subunits, the activation of membrane-bound PHOX, and the production of ROS. Therapeutic anti-inflammatories which prevent DA neurodegeneration in PD models, including anti-inflammatory cytokines, morphinan compounds, NADPH oxidase inhibitors, $\mathrm{NF}-\kappa \mathrm{B}$ inhibitors, and $\beta 2-\mathrm{AR}$ agonists, all function to inhibit the activation of the PHOX complex and ROS production in microglial cells.

signaling pathways $[127,128]$. Furthermore, higher levels of markers for oxidative stress were found in patients with PD, but the origin and response of these markers to L-DOPA therapy appear to be controversial [129]. However, given the central nature of microglial cells and neuroinflammation in the pathogenesis of $\mathrm{PD}$, it is important to determine the role of L-DOPA therapy on the redox reaction of microglial cells. It has been found that the oxidative stress of peripheral blood mononuclear cells (PBMCS) from patients with PD appears to be higher than healthy patients, but L-DOPA therapy actually appears to lower the redox response of these PBMCs [130]. Therefore, while L-DOPA-induced oxidative stress may play an important role in the direct toxicity of DA neurons seen in progressive PD, the effect of L-DOPA therapy on the oxidative stress response of macrophages and microglial cells and its direct damage on DA neurons is still not determined, and the anti-inflammatory effects of LDOPA therapy may actually play a role in short-term therapy to help to protect DA-neurons from inflammatory damage mediated by activated microglial cells.

\section{References}

[1] K. A. Jellinger, "The pathology of Parkinson's disease," Advances in Neurology, vol. 86, pp. 55-72, 2001.

[2] M. H. Polymeropoulos, C. Lavedan, E. Leroy et al., "Mutation in the $\alpha$-synuclein gene identified in families with Parkinson's disease," Science, vol. 276, no. 5321, pp. 2045-2047, 1997.

[3] M. Sun, J. C. Latourelle, G. F. Wooten et al., "Influence of heterozygosity for Parkin mutation on onset age in familial parkinson disease: the genePD study," Archives of Neurology, vol. 63, no. 6, pp. 826-832, 2006.

[4] V. Bonifati, Y. H. Wu-Chou, D. Schweiger, A. Di Fonzo, C. S. Lu, and B. Oostra, "LRRK2 mutation analysis in parkinson disease families with evidence of linkage to PARK8," Neurology, vol. 70, no. 24, pp. 2348-2349, 2008. 
[5] Y. H. Weng, Y. H. W. Chou, W. S. Wu et al., "PINK1 mutation in Taiwanese early-onset parkinsonism: clinical, genetic, and dopamine transporter studies," Journal of Neurology, vol. 254, no. 10, pp. 1347-1355, 2007.

[6] P. M. Abou-Sleiman, D. G. Healy, N. Quinn, A. J. Lees, and N. W. Wood, "The role of pathogenic DJ-1 mutations in Parkinson's disease," Annals of Neurology, vol. 54, no. 3, pp. 283-286, 2003.

[7] M. S. Goldberg, A. Pisani, M. Haburcak et al., "Nigrostriatal dopaminergic deficits and hypokinesia caused by inactivation of the familial parkinsonism-linked gene DJ-1," Neuron, vol. 45, no. 4, pp. 489-496, 2005.

[8] M. Alam and W. J. Schmidt, "Rotenone destroys dopaminergic neurons and induces parkinsonian symptoms in rats," Behavioural Brain Research, vol. 136, no. 1, pp. 317-324, 2002.

[9] A. D. Ebert, J. H. Hoo, and M. C. Bohn, "Progressive degeneration of dopamine neurons in 6-hydroxydopamine rat model of Parkinson's disease does not involve activation of caspase-9 and caspase-3," Journal of Neuroscience Research, vol. 86, no. 2, pp. 317-325, 2008.

[10] W. Meissner, C. Prunier, D. Guilloteau, S. Chalon, C. E. Gross, and E. Bezard, "Time-course of nigrostriatal degeneration in a progressive MPTP-lesioned macaque model of Parkinson's disease," Molecular Neurobiology, vol. 28, no. 3, pp. 209-218, 2003.

[11] E. C. Hirsch, S. Hunot, and A. Hartmann, "Neuroinflammatory processes in Parkinson's disease," Parkinsonism and Related Disorders, vol. 11, supplement 1, pp. S9-S15, 2005.

[12] R. L. Mosley, E. J. Benner, I. Kadiu et al., "Neuroinflammation, oxidative stres and the pathogenesis of Parkinson's disease," Clinical Neurosicence Research, vol. 6, no. 5, pp. 261281, 2006.

[13] A. L. Bartels and K. L. Leenders, "Neuroinflammation in the pathophysiology of Parkinson's disease: evidence from animal models to human in vivo studies with [11C]-PK11195 PET," Movement Disorders, vol. 22, no. 13, pp. 1852-1856, 2007.

[14] S. K. Van Den Eeden, C. M. Tanner, A. L. Bernstein et al., "Incidence of Parkinson's disease: variation by age, gender, and race/ethnicity," American Journal of Epidemiology, vol. 157, no. 11, pp. 1015-1022, 2003.

[15] J. H. Baik, R. Picetti, A. Saiardi et al., "Parkinsonianlike locomotor impairment in mice lacking dopamine D2 receptors," Nature, vol. 377, no. 6548, pp. 424-428, 1995.

[16] Y. Wang, R. Xu, T. Sasaoka, S. Tonegawa, M. P. Kung, and E. B. Sankoorikal, "Dopamine D2 long receptor-deficient mice display alterations in striatum-dependent functions," Journal of Neuroscience, vol. 20, no. 22, pp. 8305-8314, 2000.

[17] S. C. Fowler, T. J. Zarcone, E. Vorontsova, and R. Chen, "Motor and associative deficits in D2 dopamine receptor knockout mice," International Journal of Developmental Neuroscience, vol. 20, no. 3-5, pp. 309-321, 2002.

[18] P. Jenner, "Dopamine agonists, receptor selectivity and dyskinesia induction in Parkinson's disease," Current Opinion in Neurology, vol. 16, supplement 1, pp. S3-S7, 2003.

[19] B. Liu and J. S. Hong, "Role of microglia in inflammationmediated neurodegenerative diseases: mechanisms and strategies for therapeutic intervention," Journal of Pharmacology and Experimental Therapeutics, vol. 304, no. 1, pp. 1-7, 2003.

[20] P. T. Nelson, L. A. Soma, and E. Lavi, "Microglia in diseases of the central nervous system," Annals of Medicine, vol. 34, no. 7-8, pp. 491-500, 2002.
[21] G. J. Guillemin and B. J. Brew, "Microglia, macrophages, perivascular macrophages, and pericytes: a review of function and identification," Journal of Leukocyte Biology, vol. 75, no. 3, pp. 388-397, 2004.

[22] W. Dauer and S. Przedborski, "Parkinson's disease: mechanisms and models," Neuron, vol. 39, no. 6, pp. 889-909, 2003.

[23] H. M. Gao, P. T. Kotzbauer, K. Uryu, S. Leight, J. Q. Trojanowski, and V. M. Y. Lee, "Neuroinflammation and oxidation/nitration of $\alpha$-synuclein linked to dopaminergic neurodegeneration," Journal of Neuroscience, vol. 28, no. 30, pp. 7687-7698, 2008.

[24] M. L. Block and J. S. Hong, "Chronic microglial activation and progressive dopaminergic neurotoxicity," Biochemical Society Transactions, vol. 35, no. 5, pp. 1127-1132, 2007.

[25] A. Członkowska, M. Kohutnicka, I. Kurkowska-Jastrzębska, and A. Członkowski, "Microglial reaction in MPTP (1methyl-4-phenyl-1,2,3,6-tetrahydropyridine) induced Parkinson's disease mice model," Neurodegeneration, vol. 5, no. 2, pp. 137-143, 1996.

[26] W. G. Kim, R. P. Mohney, B. Wilson, G. H. Jeohn, B. Liu, and J. S. Hong, "Regional difference in susceptibility to lipopolysaccharide-induced neurotoxicity in the rat brain: role of microglia," Journal of Neuroscience, vol. 20, no. 16, pp. 6309-6316, 2000.

[27] A. Ghosh, A. Roy, X. Liu et al., "Selective inhibition of NF- $\kappa$ B activation prevents dopaminergic neuronal loss in a mouse model of Parkinson's disease," Proceedings of the National Academy of Sciences of the United States of America, vol. 104, no. 47, pp. 18754-18759, 2007.

[28] F. Cicchetti, A. L. Brownell, K. Williams, Y. I. Chen, E. Livni, and O. Isacson, "Neuroinflammation of the nigrostriatal pathway during progressive 6-OHDA dopamine degeneration in rats monitored by immunohistochemistry and PET imaging," European Journal of Neuroscience, vol. 15, no. 6, pp. 991-998, 2002.

[29] P. L. McGeer, S. Itagaki, B. E. Boyes, and E. G. McGeer, "Reactive microglia are positive for HLA-DR in the substantia nigra of Parkinson's and Alzheimer's disease brains," Neurology, vol. 38, no. 8, pp. 1285-1291, 1988.

[30] T. Nagatsu, M. Mogi, H. Ichinose, and A. Togari, "Changes in cytokines and neurotrophins in Parkinson's disease," Journal of Neural Transmission, Supplement, no. 60, pp. 277-290, 2000.

[31] M. Mogi, M. Harada, T. Kondob et al., "Interleukin-1 $\beta$, interleukin-6, epidermal growth factor and transforming growth factor- $\alpha$ are elevated in the brain from parkinsonian patients," Neuroscience Letters, vol. 180, no. 2, pp. 147-150, 1994.

[32] H. Bessler, R. Djaldetti, H. Salman, M. Bergman, and M. Djaldetti, "IL-1 $\beta$, IL-2, IL-6 and TNF- $\alpha$ production by peripheral blood mononuclear cells from patients with Parkinson's disease," Biomedicine and Pharmacotherapy, vol. 53, no. 3, pp. 141-145, 1999.

[33] G. A. Qureshi, S. Baig, I. Bednar, P. Sodersten, G. Forsberg, and A. Siden, "Increased cerebrospinal fluid concentration of nitrite ire Parkinson's disease," NeuroReport, vol. 6, no. 12, pp. 1642-1644, 1995.

[34] S. Hunot, F. Boissière, B. Faucheux et al., "Nitric oxide synthase and neuronal vulnerability in Parkinson's disease," Neuroscience, vol. 72, no. 2, pp. 355-363, 1996.

[35] T. Nagatsu, M. Mogi, H. Ichinose, and A. Togari, "Cytokines in Parkinson's disease," Journal of Neural Transmission, Supplement, no. 58, pp. 143-151, 2000. 
[36] M. E. Lull and M. L. Block, "Microglial activation and chronic neurodegeneration," Neurotherapeutics, vol. 7, no. 4, pp. 354-365, 2010.

[37] B. Liu, H. M. Gao, J. Y. Wang, G. H. Jeohn, C. L. Cooper, and J. S. Hong, "Role of nitric oxide in inflammation-mediated neurodegeneration," Annals of the New York Academy of Sciences, vol. 962, pp. 318-331, 2002.

[38] V. Shukla, S. K. Mishra, and H. C. Pant, "Oxidative stress in neurodegeneration," Advances in Pharmacological Sciences, vol. 2011, Article ID 572634, 13 pages, 2011.

[39] A. D. Kraft and G. Jean Harry, "Features of microglia and neuroinflammation relevant to environmental exposure and neurotoxicity," International Journal of Environmental Research and Public Health, vol. 8, no. 7, pp. 2980-3018, 2011.

[40] U. K. Hanisch, "Microglia as a source and target of cytokines," GLIA, vol. 40, no. 2, pp. 140-155, 2002.

[41] K. Heese, C. Hock, and U. Otten, "Inflammatory signals induce neurotrophin expression in human microglial cells," Journal of Neurochemistry, vol. 70, no. 2, pp. 699-707, 1998.

[42] N. P. Whitney, T. M. Eidem, H. Peng, Y. Huang, and J. C. Zheng, "Inflammation mediates varying effects in neurogenesis: relevance to the pathogenesis of brain injury and neurodegenerative disorders," Journal of Neurochemistry, vol. 108, no. 6, pp. 1343-1359, 2009.

[43] K. Heese, B. L. Fiebich, J. Bauer, and U. Otten, "NF$\kappa \mathrm{B}$ modulates lipopolysaccharide-induced microglial nerve growth factor expression," GLIA, vol. 22, no. 4, pp. 401-407, 1998.

[44] M. Yoneyama, T. Shiba, S. Hasebe, and K. Ogita, "Adult neurogenesis is regulated by endogenous factors produced during neurodegeneration," Journal of Pharmacological Sciences, vol. 115, no. 4, pp. 425-432, 2011.

[45] D. M. Bronstein, I. Perez-Otano, V. Sun et al., "Gliadependent neurotoxicity and neuroprotection in mesencephalic cultures," Brain Research, vol. 704, no. 1, pp. 112116, 1995.

[46] E. Araki, C. Forster, J. M. Dubinsky, M. E. Ross, and C. Iadecola, "Cyclooxygenase-2 inhibitor NS-398 protects neuronal cultures from lipopolysaccharide-induced neurotoxicity," Stroke, vol. 32, no. 10, pp. 2370-2375, 2001.

[47] W. Zhang, T. Wang, Z. Pei et al., "Aggregated $\alpha$-synuclein activates microglia: a process leading to disease progression in Parkinson's disease," The FASEB Journal, vol. 19, no. 6, pp. 533-542, 2005.

[48] Y. Itzhak, J. L. Martin, and S. F. Ali, "Methamphetamineand 1-methyl-4-phenyl-1,2,3,6-tetrahydropyridine- induced dopaminergic neurotoxicity in inducible nitric oxide synthase-deficient mice," Synapse, vol. 34, no. 4, pp. 305-312, 1999.

[49] G. T. Liberatore, V. Jackson-Lewis, S. Vukosavic et al., "Inducible nitric oxide synthase stimulates dopaminergic neurodegeneration in the MPTP model of Parkinson disease," Nature Medicine, vol. 5, no. 12, pp. 1403-1409, 1999.

[50] T. Dehmer, J. Lindenau, S. Haid, J. Dichgans, and J. B. Schulz, "Deficiency of inducible nitric oxide synthase protects against MPTP toxicity in vivo," Journal of Neurochemistry, vol. 74, no. 5, pp. 2213-2216, 2000.

[51] Y. Du, Z. Ma, S. Lin et al., "Minocycline prevents nigrostriatal dopaminergic neurodegeneration in the MPTP model of Parkinson's disease," Proceedings of the National Academy of Sciences of the United States of America, vol. 98, no. 25, pp. 14669-14674, 2001.
[52] S. A. Factor, J. Sanchez-Ramos, and W. J. Weiner, "Trauma as an etiology of parkinsonism: a historical review of the concept," Movement Disorders, vol. 3, no. 1, pp. 30-36, 1988.

[53] Z. Ling, D. A. Gayle, S. Y. Ma et al., "In utero bacterial endotoxin exposure causes loss of tyrosine hydroxylase neurons in the postnatal rat midbrain," Movement Disorders, vol. 17, no. 1, pp. 116-124, 2002.

[54] A. S. Baldwin Jr., "The NF- $\kappa \mathrm{B}$ and $\mathrm{I} \kappa \mathrm{B}$ proteins: new discoveries and insights," Annual Review of Immunology, vol. 14, pp. 649-681, 1996.

[55] A. S. Baldwin Jr., "Series introduction: the transcription factor NF-kappaB and human disease," The Journal of Clinical Investigation, vol. 107, no. 1, pp. 3-6, 2001.

[56] E. M. Boyle Jr., J. C. Kovacich, C. A. Hebert et al., "Inhibition of interleukin-8 blocks myocardial ischemia-reperfusion injury," Journal of Thoracic and Cardiovascular Surgery, vol. 116, no. 1, pp. 114-121, 1998.

[57] B. Chandrasekar and G. L. Freeman, "Induction of nuclear factor $\kappa \mathrm{B}$ and activation protein 1 in postischemic myocardium," FEBS Letters, vol. 401, no. 1, pp. 30-34, 1997.

[58] V. Jackson-Lewis and R. J. Smeyne, "MPTP and SNpc DA neuronal vulnerability: role of dopamine, superoxide and nitric oxide in neurotoxicity. Minireview," Neurotoxicity Research, vol. 7, no. 3, pp. 193-201, 2005.

[59] Y. Liu, L. Qin, G. Li et al., "Dextromethorphan protects dopaminergic neurons against inflammation-mediated degeneration through inhibition of microglial activation," Journal of Pharmacology and Experimental Therapeutics, vol. 305, no. 1, pp. 212-218, 2003.

[60] L. Qian, M. L. Block, S. J. Wei et al., "Interleukin-10 protects lipopolysaccharide-induced neurotoxicity in primary midbrain cultures by inhibiting the function of NADPH oxidase," Journal of Pharmacology and Experimental Therapeutics, vol. 319, no. 1, pp. 44-52, 2006.

[61] L. Qian, S. T. Kai, S. J. Wei et al., "Microglia-mediated neurotoxicity is inhibited by morphine through an opioid receptor-independent reduction of NADPH oxidase activity," Journal of Immunology, vol. 179, no. 2, pp. 1198-1209, 2007.

[62] D. A. Loeffler, A. J. DeMaggio, P. L. Juneau, M. K. Havaich, and P. A. LeWitt, "Effects of enhanced striatal dopamine turnover in vivo on glutathione oxidation," Clinical Neuropharmacology, vol. 17, no. 4, pp. 370-379, 1994.

[63] S. Sanlioglu, C. M. Williams, L. Samavati et al., "Lipopolysaccharide induces rac1-dependent reactive oxygen species formation and coordinates tumor necrosis factor- $\alpha$ secretion through IKK regulation of NF- $\kappa \mathrm{B}$," Journal of Biological Chemistry, vol. 276, no. 32, pp. 30188-30198, 2001.

[64] H. Neumann, "Control of glial immune function by neurons," GLIA, vol. 36, no. 2, pp. 191-199, 2001.

[65] K. Biber, H. Neumann, K. Inoue, and H. W. G. M. Boddeke, "Neuronal "On" and "Off" signals control microglia," Trends in Neurosciences, vol. 30, no. 11, pp. 596-602, 2007.

[66] J. M. Pocock and H. Kettenmann, "Neurotransmitter receptors on microglia," Trends in Neurosciences, vol. 30, no. 10, pp. 527-535, 2007.

[67] A. N. Barclay, G. J. Wright, G. Brooke, and M. H. Brown, "CD200 and membrane protein interactions in the control of myeloid cells," Trends in Immunology, vol. 23, no. 6, pp. 285-290, 2002.

[68] A. Lyons, E. J. Downer, S. Crotty, Y. M. Nolan, K. H. G. Mills, and M. A. Lynch, "CD200 ligand-receptor interaction modulates microglial activation in vivo and in vitro: a role for IL-4," Journal of Neuroscience, vol. 27, no. 31, pp. 8309-8313, 2007. 
[69] R. H. Hoek, S. R. Ruuls, C. A. Murphy et al., "Downregulation of the macrophage lineage through interaction with OX2 (CD200)," Science, vol. 290, no. 5497, pp. 1768 $1771,2000$.

[70] G. J. Wright, M. J. Puklavec, A. C. Willis et al., "Lymphoid/neuronal cell surface OX2 glycoprotein recognizes a novel receptor on macrophages implicated in the control of their function," Immunity, vol. 13, no. 2, pp. 233-242, 2000.

[71] X. J. Wang, S. Zhang, Z. Q. Yan et al., "Impaired CD200CD200R-mediated microglia silencing enhances midbrain dopaminergic neurodegeneration: roles of aging, superoxide, NADPH oxidase, and p38 MAPK," Free Radical Biology and Medicine, vol. 50, no. 9, pp. 1094-1106, 2011.

[72] L. Qin, Y. Liu, T. Wang et al., "NADPH oxidase mediates lipopolysaccharide-induced neurotoxicity and proinflammatory gene expression in activated microglia," Journal of Biological Chemistry, vol. 279, no. 2, pp. 1415-1421, 2004.

[73] L. Qian, X. Gao, Z. Pei et al., "NADPH oxidase inhibitor DPI is neuroprotective at femtomolar concentrations through inhibition of microglia over-activation," Parkinsonism and Related Disorders, vol. 13, supplement 3, pp. S316-S320, 2007.

[74] H. Kono, I. Rusyn, T. Uesugi et al., "Diphenyleneiodonium sulfate, an NADPH oxidase inhibitor, prevents early alcoholinduced liver injury in the rat," American Journal of Physiology, vol. 280, no. 5, pp. G1005-G1012, 2001.

[75] J. S. Gujral, J. A. Hinson, A. Farhood, and H. Jaeschke, "NADPH oxidase-derived oxidant stress is critical for neutrophil cytotoxicity during endotoxemia," American Journal of Physiology, vol. 287, no. 1, pp. G243-G252, 2004.

[76] S. Pawate, Q. Shen, F. Fan, and N. R. Bhat, "Redox regulation of glial inflammatory response to lipopolysaccharide and interferon $\gamma$," Journal of Neuroscience Research, vol. 77, no. 4, pp. 540-551, 2004.

[77] J. E. Le Belle, N. M. Orozco, A. A. Paucar et al., "Proliferative neural stem cells have high endogenous ROS levels that regulate self-renewal and neurogenesis in a PI3K/Akt-dependant manner," Cell Stem Cell, vol. 8, no. 1, pp. 59-71, 2011.

[78] Q. Li and J. F. Engelhardt, "Interleukin- $1 \beta$ induction of $\mathrm{NF} \kappa \mathrm{B}$ is partially regulated by $\mathrm{H}_{2} \mathrm{O}_{2}$-mediated activation of $\mathrm{NF} \kappa \mathrm{B}$ inducing kinase," Journal of Biological Chemistry, vol. 281, no. 3, pp. 1495-1505, 2006.

[79] B. Halliwell and P. Jenner, "Impaired clearance of oxidised proteins in neurodegenerative diseases," Lancet, vol. 351, no. 9114, p. 1510, 1998.

[80] P. Jenner, "Oxidative mechanisms in nigral cell death in Parkinson's disease," Movement Disorders, vol. 13, supplement 1, pp. 24-34, 1998.

[81] P. Jenner and C. W. Olanow, "Understanding cell death in Parkinson's disease," Annals of Neurology, vol. 44, no. 3, supplement 1, pp. S72-S84, 1998.

[82] K. Jomova, D. Vondrakova, M. Lawson, and M. Valko, "Metals, oxidative stress and neurodegenerative disorders," Molecular and Cellular Biochemistry, vol. 345, no. 1-2, pp. 91104, 2010.

[83] M. J. Morgan and Z. G. Liu, "Crosstalk of reactive oxygen species and NF- $\kappa$ B signaling," Cell Research, vol. 21, no. 1, pp. 103-115, 2011.

[84] P. M. Flood, L. Qian, L. J. Peterson et al., “Transcriptional factor NF-kappaB as a target for therapy in Parkinson's disease," Parkinson's Disease, vol. 2011, Article ID 216298, 8 pages, 2011.

[85] H. Zhong, M. J. May, E. Jimi, and S. Ghosh, "The phosphorylation status of nuclear NF- $\kappa$ B determines its association with CBP/p300 or HDAC-1," Molecular Cell, vol. 9, no. 3, pp. 625-636, 2002.

[86] I. Jaspers, W. Zhang, A. Fraser, J. M. Samet, and W. Reed, "Hydrogen peroxide has opposing effects on IKK activity and $\mathrm{I} \kappa \mathrm{B} \alpha$ breakdown in airway epithelial cells," American Journal of Respiratory Cell and Molecular Biology, vol. 24, no. 6, pp. 769-777, 2001.

[87] Y. Jing, J. Yang, Y. Wang et al., "Alteration of subcellular redox equilibrium and the consequent oxidative modification of nuclear factor $\kappa \mathrm{B}$ are critical for anticancer cytotoxicity by emodin, a reactive oxygen species-producing agent," Free Radical Biology and Medicine, vol. 40, no. 12, pp. 2183-2197, 2006.

[88] Y. Wang, X. Huang, H. Cang et al., "The endogenous reactive oxygen species promote NF- $\kappa \mathrm{B}$ activation by targeting on activation of NF- $\kappa \mathrm{B}$-inducing kinase in oral squamous carcinoma cells," Free Radical Research, vol. 41, no. 9, pp. 963-971, 2007.

[89] Y. Wang, J. Yang, J. Yi et al., "Redox sensing by proteins: oxidative modifications on cysteines and the consequent events," Antioxid Redox Signal, vol. 16, no. 7, pp. 649-657, 2012.

[90] F. Zhang, L. Qian, P. M. Flood, J. S. Shi, J. S. Hong, and H. M. Gao, "Inhibition of $\mathrm{I} \kappa \mathrm{B}$ kinase- $\beta$ protects dopamine neurons against lipopolysaccharide-induced neurotoxicity," Journal of Pharmacology and Experimental Therapeutics, vol. 333, no. 3, pp. 822-833, 2010.

[91] S. J. Chinta and J. K. Andersen, "Nitrosylation and nitration of mitochondrial complex i in Parkinson's disease," Free Radical Research, vol. 45, no. 1, pp. 53-58, 2011.

[92] E. Clementi, G. C. Brown, M. Feelisch, and S. Moncada, "Persistent inhibition of cell respiration by nitric oxide: crucial role of S-nitrosylation of mitochondrial complex I and protective action of glutathione," Proceedings of the National Academy of Sciences of the United States of America, vol. 95, no. 13, pp. 7631-7636, 1998.

[93] C. Isobe, T. Abe, and Y. Terayama, "Levels of reduced and oxidized coenzymeQ-10 and 8-hydroxy-2'-deoxyguanosine in the cerebrospinal fluid of patients with living Parkinson's disease demonstrate that mitochondrial oxidative damage and/or oxidative DNA damage contributes to the neurodegenerative process," Neuroscience Letters, vol. 469, no. 1, pp. 159-163, 2010.

[94] C. Isobe, T. Abe, T. Kikuchi, T. Murata, C. Sato, and Y. Terayama, "Cabergoline scavenges peroxynitrite enhanced by L-DOPA therapy in patients with Parkinson's disease," European Journal of Neurology, vol. 13, no. 4, pp. 346-350, 2006.

[95] M. Tomás-Camardiel, I. Rite, A. J. Herrera et al., "Minocycline reduces the lipopolysaccharide-induced inflammatory reaction, peroxynitrite-mediated nitration of proteins, disruption of the blood-brain barrier, and damage in the nigral dopaminergic system," Neurobiology of Disease, vol. 16, no. 1, pp. 190-201, 2004.

[96] M. F. Beal, "Oxidatively modified proteins in aging and disease," Free Radical Biology and Medicine, vol. 32, no. 9, pp. 797-803, 2002

[97] I. Kurkowska-Jastrzebska, A. Wrońska, M. S. Kohutnicka, A. Czlonkowski, and A. Czlonkowska, "The inflammatory reaction following 1-methyl-4-phenyl-1,2,3,6- tetrahydropyridine intoxication in mouse," Experimental Neurology, vol. 156, no. 1, pp. 50-61, 1999.

[98] A. Castaño, A. J. Herrera, J. Cano, and A. Machado, "The degenerative effect of a single intranigral injection of LPS 
on the dopaminergic system is prevented by dexamethasone, and not mimicked by rh-TNF- $\alpha$ IL- $1 \beta$ IFN- $\gamma$," Journal of Neurochemistry, vol. 81, no. 1, pp. 150-157, 2002.

[99] K. Sairam, K. S. Saravanan, R. Banerjee, and K. P. Mohanakumar, "Non-steroidal anti-inflammatory drug sodium salicylate, but not diclofenac or celecoxib, protects against 1methyl-4-phenyl pyridinium-induced dopaminergic neurotoxicity in rats," Brain Research, vol. 966, no. 2, pp. 245-252, 2003.

[100] F. Zhang, L. Qian, P. M. Flood et al., "Inhibition of IkappaB kinase-beta protects dopamine neurons against lipopolysaccharide-induced neurotoxicity," Journal of Pharmacology and Experimental Therapeutics, vol. 333, no. 3, pp. 822-833, 2010.

[101] A. Bernardo, L. Gasparini, E. Ongini, and L. Minghetti, "Dynamic regulation of microglial functions by the nonsteroidal anti-inflammatory drug NCX 2216: implications for chronic treatments of neurodegenerative diseases," Neurobiology of Disease, vol. 22, no. 1, pp. 25-32, 2006.

[102] A. Bernardo, M. A. Ajmone-Cat, L. Gasparini, E. Ongini, and L. Minghetti, "Nuclear receptor peroxisome proliferatoractivated receptor- $\gamma$ is activated in rat microglial cells by the anti-inflammatory drug HCT1026, a derivative of flurbiprofen," Journal of Neurochemistry, vol. 92, no. 4, pp. 895-903, 2005.

[103] K. Strle, J. H. Zhou, W. H. Shen et al., "Interleukin-10 in the brain," Critical Reviews in Immunology, vol. 21, no. 5, pp. 427-449, 2001.

[104] K. W. Moore, R. De Waal Malefyt, R. L. Coffman, and A. O'Garra, "Interleukin-10 and the interleukin-10 receptor," Annual Review of Immunology, vol. 19, pp. 683-765, 2001.

[105] L. C. Johnston, X. Su, K. Maguire-Zeiss et al., "Human interleukin-10 gene transfer is protective in a rat model of parkinson's disease," Molecular Therapy, vol. 16, no. 8, pp. 1392-1399, 2008.

[106] Y. Zhu, G. Y. Yang, B. Ahlemeyer et al., "Transforming growth factor- $\beta 1$ increases bad phosphorylation and protects neurons against damage," Journal of Neuroscience, vol. 22, no. 10, pp. 3898-3909, 2002.

[107] J. H. Prehn and J. Krieglstein, "Opposing effects of transforming growth factor- $\beta 1$ on glutamate neurotoxicity," $\mathrm{Neu}$ roscience, vol. 60, no. 1, pp. 7-10, 1994.

[108] L. Qian, S. J. Wei, D. Zhang et al., "Potent anti-inflammatory and neuroprotective effects of tgf- $\beta 1$ are mediated through the inhibition of erk and p47phox-Ser345 phosphorylation and translocation in microglia," Journal of Immunology, vol. 181, no. 1, pp. 660-668, 2008.

[109] W. Zhang, T. Wang, L. Qin et al., "Neuroprotective effect of dextromethorphan in the MPTP Parkinson's disease model: role of NADPH oxidase," The FASEB Journal Biology, vol. 18, no. 3, pp. 589-591, 2004.

[110] W. Zhang, L. Qin, T. Wang et al., “3-Hydroxymorphinan is neurotrophic to dopaminergic neurons and is also neuroprotective against LPS-induced neurotoxicity," The FASEB Journal, vol. 19, no. 3, pp. 395-397, 2005.

[111] W. Zhang, E. J. Shin, T. Wang et al., "3-Hydroxymorphinan, a metabolite of dextromethorphan, protects nigrostriatal pathway against MPTP-elicited damage both in vivo and in vitro," The FASEB Journal, vol. 20, no. 14, pp. 2496-2511, 2006.

[112] L. Liu, K. Resch, and V. Kaever, "Inhibition of lymphocyte proliferation by the anti-arthritic drug sinomenine," International Journal of Immunopharmacology, vol. 16, no. 8, pp. 685-691, 1994.
[113] L. Liu, E. Buchner, D. Beitze et al., "Amelioration of rat experimental arthritides by treatment with the alkaloid sinomenine," International Journal of Immunopharmacology, vol. 18, no. 10, pp. 529-543, 1996.

[114] W. C. Koff, A. V. Fann, M. A. Dunegan, and L. B. Lachman, "Catecholamine-induced suppression of interleukin-1 production," Lymphokine Research, vol. 5, no. 4, pp. 239-247, 1986.

[115] T. van der Poll, J. Jansen, E. Endert, H. P. Sauerwein, and S. J. H. Van Deventer, "Noradrenaline inhibits lipopolysaccharide-induced tumor necrosis factor and interleukin 6 production in human whole blood," Infection and Immunity, vol. 62, no. 5, pp. 2046-2050, 1994.

[116] L. Sekut, B. R. Champion, K. Page, J. A. Menius, and K. M. Connolly, "Anti-inflammatory activity of salmeterol: downregulation of cytokine production," Clinical and Experimental Immunology, vol. 99, no. 3, pp. 461-466, 1995.

[117] A. Severn, N. T. Rapson, C. A. Hunter, and F. Y. Liew, "Regulation of tumor necrosis factor production by adrenaline and $\beta$-adrenergic agonists," Journal of Immunology, vol. 148, no. 11, pp. 3441-3445, 1992.

[118] P. Farmer and J. Pugin, "beta-adrenergic agonists exert their "anti-inflammatory" effects in monocytic cells through the IkappaB/NF-kappaB pathway," American Journal of Physiology, vol. 279, no. 4, pp. L675-L682, 2000.

[119] N. W. Kin and V. M. Sanders, "It takes nerve to tell T and B cells what to do," Journal of Leukocyte Biology, vol. 79, no. 6, pp. 1093-1104, 2006.

[120] P. Panina-Bordignon, D. Mazzeo, P. D. Lucia et al., "Beta2agonists prevent Th1 development by selective inhibition of interleukin 12," The Journal of Clinical Investigation, vol. 100, no. 6, pp. 1513-1519, 1997.

[121] L. Qian, H. M. Wu, S. H. Chen et al., "beta2-adrenergic receptor activation prevents rodent dopaminergic neurotoxicity by inhibiting microglia via a novel signaling pathway," The Journal of Immunology, vol. 186, no. 7, pp. 4443-4454, 2011.

[122] K. S. Tan, A. G. Nackley, K. Satterfield, W. Maixner, L. Diatchenko, and P. M. Flood, "Beta2 adrenergic receptor activation stimulates pro-inflammatory cytokine production in macrophages via PKA- and NF-kappaB-independent mechanisms," Cellular Signalling, vol. 19, no. 2, pp. 251-260, 2007.

[123] K. A. Maguire-Zeiss, D. W. Short, and H. J. Federoff, "Synuclein, dopamine and oxidative stress: co-conspirators in Parkinson's disease?" Molecular Brain Research, vol. 134, no. 1, pp. 18-23, 2005.

[124] S. Gandhi and N. W. Wood, "Molecular pathogenesis of Parkinson's disease," Human Molecular Genetics, vol. 14, no. 18, pp. 2749-2755, 2005.

[125] D. G. Graham, "Oxidative pathways for catecholamines in the genesis of neuromelanin and cytotoxic quinones," Molecular Pharmacology, vol. 14, no. 4, pp. 633-643, 1978.

[126] A. N. Basma, E. J. Morris, W. J. Nicklas, and H. M. Geller, "L-DOPA cytotoxicity to PC12 cells in culture is via its autoxidation," Journal of Neurochemistry, vol. 64, no. 2, pp. 825-832, 1995.

[127] C. M. Jin, Y. J. Yang, H. S. Huang, M. Kai, and M. K. Lee, "Mechanisms of L-DOPA-induced cytotoxicity in rat adrenal pheochromocytoma cells: implication of oxidative stress-related kinases and cyclic AMP," Neuroscience, vol. 170, no. 2, pp. 390-398, 2010.

[128] E. A. Sabens Liedhegner, K. M. Steller, and J. J. Mieyal, "Levodopa activates apoptosis signaling kinase 1 (ASK1) and promotes apoptosis in a neuronal model: implications for 
the treatment of Parkinson's disease," Chemical Research in Toxicology, vol. 24, no. 10, pp. 1644-1652, 2011.

[129] C. Buhmann, S. Arlt, A. Kontush et al., "Plasma and CSF markers of oxidative stress are increased in Parkinson's disease and influenced by antiparkinsonian medication," Neurobiology of Disease, vol. 15, no. 1, pp. 160-170, 2004.

[130] A. Prigione, B. Begni, A. Galbussera et al., "Oxidative stress in peripheral blood mononuclear cells from patients with Parkinson's disease: negative correlation with levodopa dosage," Neurobiology of Disease, vol. 23, no. 1, pp. 36-43, 2006. 


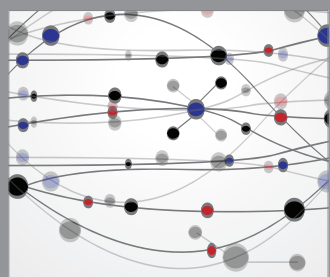

The Scientific World Journal
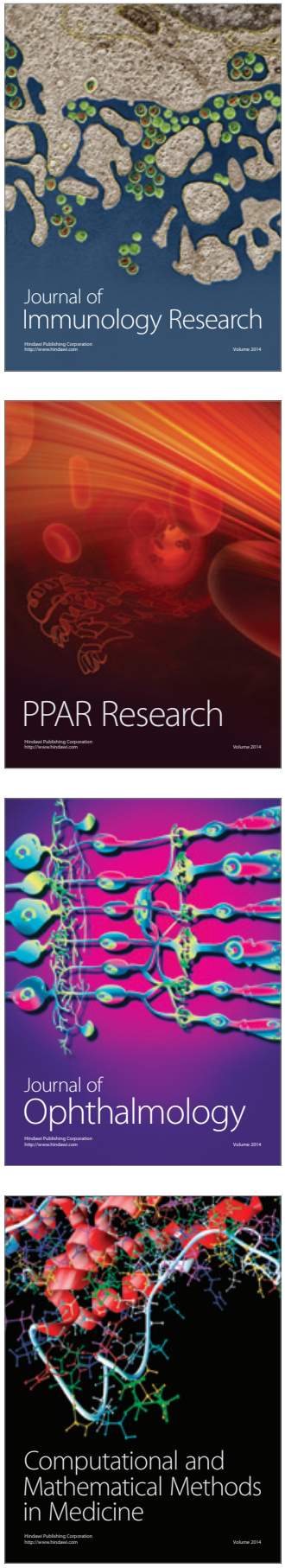

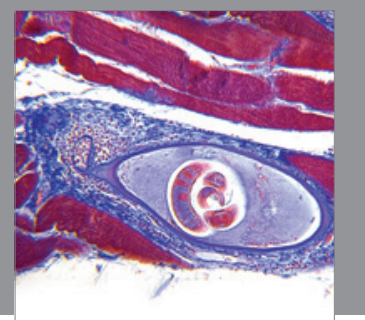

Gastroenterology

Research and Practice
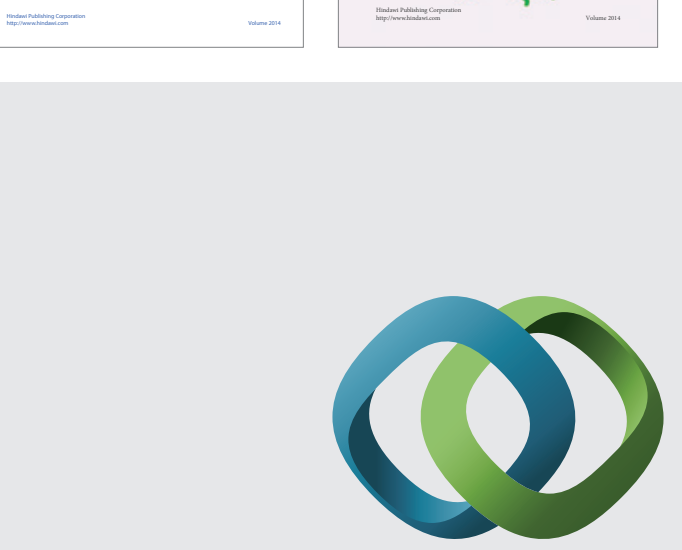

\section{Hindawi}

Submit your manuscripts at

http://www.hindawi.com
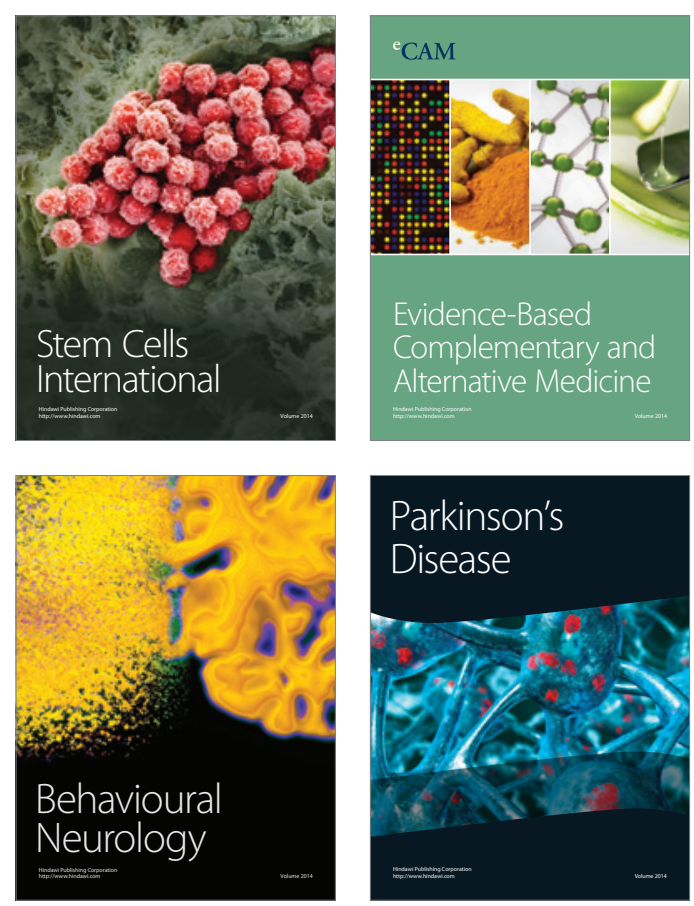

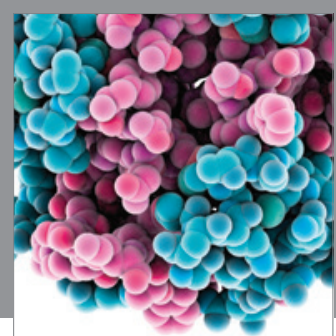

Journal of
Diabetes Research

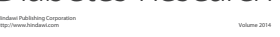

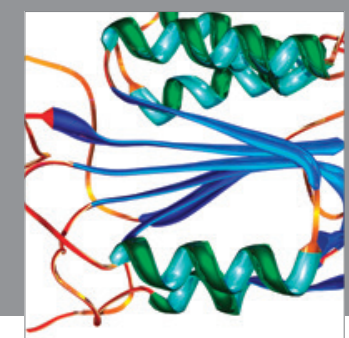

Disease Markers
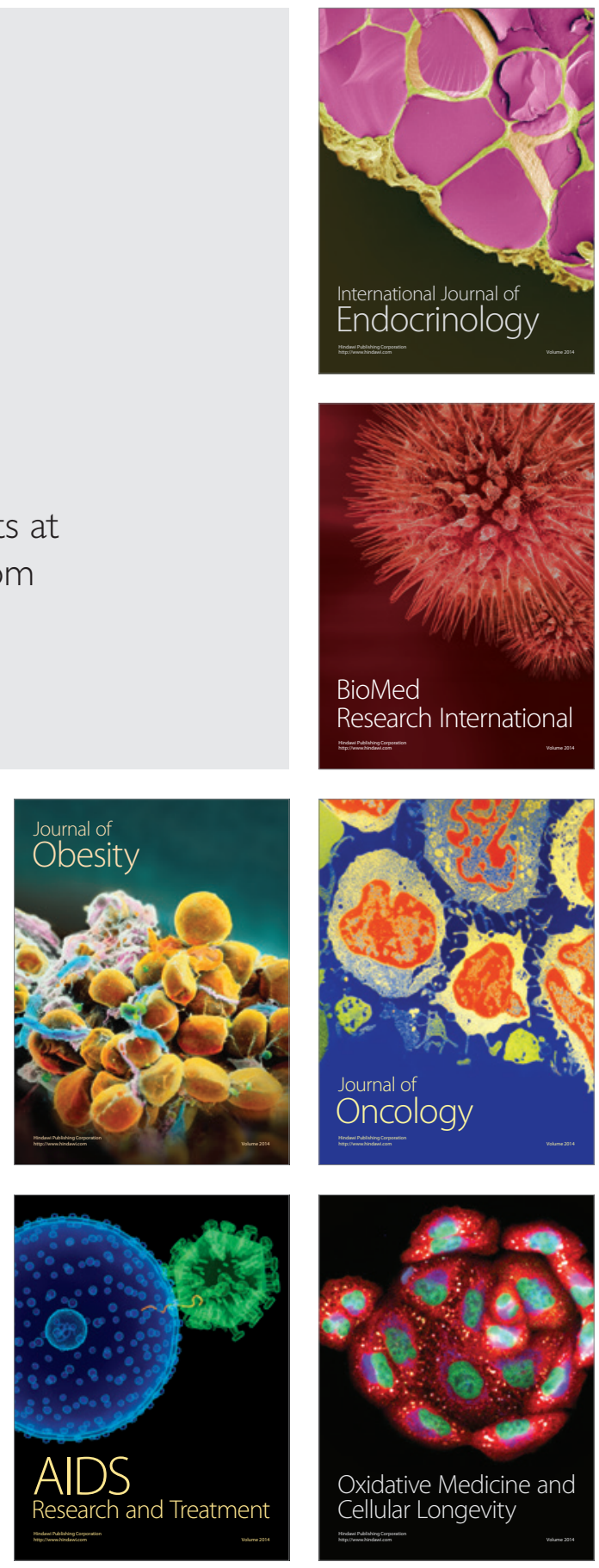